\title{
Níveis de energia metabolizável em rações pré-iniciais para frangos de corte ${ }^{1}$
}

\section{Suzany Aparecida Gomes Xavier ${ }^{2}$, José Henrique Stringhini ${ }^{3}$, Alexandre Barbosa de Brito ${ }^{2}$, Maria Auxiliadora Andrade ${ }^{3}$, Nadja Susana Mogyca Leandro ${ }^{3}$, Marcos Barcellos Café ${ }^{3}$}

\author{
1 Projeto financiado pelo CNPq e Abatedouro São Salvador. \\ 2 Programa de Pós-graduação em Ciência Animal - Universidade Federal de Goiás, Caixa Postal 131, Goiânia - GO. \\ ${ }^{3}$ Departamento de Produção Animal, Escola de Veterinária, Universidade Federal de Goiás, Caixa Postal 131, Goiânia - GO. Bolsista do \\ CNPq.
}

RESUMO - Um experimento foi conduzido com o objetivo de avaliar níveis de energia metabolizável em rações para frangos de corte na fase pré-inicial de crescimento. Foram alojados 280 pintos de 1 dia de idade, linhagem Avian Cobb em baterias aquecidas e distribuídas em um delineamento inteiramente casualizado com cinco tratamentos (2.850, 2.950, $3.000,3.050,3.150 \mathrm{kcal} / \mathrm{kg}$ de EM na ração) e quatro repetições de 14 aves por unidade experimental. Foram medidos os pesos das aves e das rações fornecidas e as sobras nos 1, 4, 7, 10, 14, 18 e 21 dias de idade e as características de desempenho determinadas (ganho de peso médio, consumo de ração e conversão alimentar) nos períodos de 1 a 7 e de 1 a 21 dias de idade. Realizou-se um ensaio de digestibilidade durante a primeira semana entre o quarto e o sétimo dias. Os resultados indicaram que os níveis EM testados influenciaram o desempenho das aves no período de 1 a 21 dias de idade, porém, os menores níveis de EM resultaram nos piores valores de digestibilidade da MS. O menor nível, $2.850 \mathrm{kcal}$ EM/kg, permitiu melhor desempenho de frangos de corte, enquanto o de $3.115 \mathrm{kcal} \mathrm{EM} / \mathrm{kg}$ promoveu melhor digestibilidade da MS em rações à base de milho e farelo de soja.

Palavras-chave: desempenho, digestibilidade, morfometria digestiva, retenção de nutrientes

\section{Metabolizable energy levels in broiler pre-starter diets}

\begin{abstract}
This experiment was carried out to evaluate the dietary metabolizable energy levels for broilers in the preinitial growth phase. A total of 280 Avian $\times$ Cobb one day old chicks was allotted to warm cages as a completely randomized design with five treatments $(2,850,2,950,3,000,3,050$, and 3,150 kcal/kg of ME in the diet) and four replicates of 14 birds per experimental unit. Bird weight and diet and orts weights were measured at 1, 4, 7, 10, 14, 18 and 21days old and the performance characteristics determined (average weight gain, feed intake, feed-to-gain ratio) from 1 to 7 and 1 to 21 days. A digestibility assay was performed during the first week between the $4^{\text {th }}$ and $7^{\text {th }}$ days. The results showed that the evaluated ME levels influenced the performance of the birds from 1 to 21 days old, however, the lowest level of ME resulted in worst DM digestibility values. The lowest levels, 2,850 kcal ME/kg, provided better broiler performance, while the 3,115 kcal $\mathrm{ME} / \mathrm{kg}$ provided better DM digestibility in corn-soybean based diets.
\end{abstract}

Key Words: digestibility, digestive organs dimension, nutrient retention, performance

\section{Introdução}

Na primeira semana de vida, os pintos apresentam características peculiares, em razão de suas limitações na digestão e absorção de nutrientes. No entanto, ainda são poucas as pesquisas envolvendo a determinação de exigências nutricionais nesta fase.

Dibner (1996) observou que vários fatores podem influenciar a taxa de crescimento precoce, como a quantidade de resíduos do saco vitelínico, a ingestão de ração e de água, bem como sua quantidade, os níveis de enzimas pancreáticas e intestinais, a área de superfície intestinal e a digestibilidade global de nutrientes. As principais razões que justificam a dieta específica na primeira semana de vida são anatomia e fisiologia do aparelho digestivo, em virtude das limitações dessas aves para digerir e absorver determinados nutrientes e da grande dificuldade de garantir a sobrevivência em ambientes frios (Penz \& Vieira, 1998; Croom et al., 1999).

Lima (1996) apresentou níveis nutricionais empregados por produtores de frangos de corte para a fase préinicial (1 a 7 dias); os níveis de proteína bruta (PB) relatados

Este artigo foi recebido em 18/9/2006 e aprovado em 9/8/2007. 
por esses autores variaram entre 21 e $22 \%$, superiores àqueles da fase inicial (20 e 21\%). Recentemente, Rostagno et al. (2005) incluíram os primeiros sete dias de criação com informações obtidas em equações de predição com dados obtidos em pesquisas realizadas na fase inicial (1 a 21 dias).

O desenvolvimento da superfície absortiva do trato digestivo das aves é fundamental para o máximo aproveitamento dos nutrientes (Mahagna \& Nir,1996). De acordo com Sklan (2001), após a eclosão, ocorre rápida transição no suprimento da energia fornecida pelos nutrientes endógenos do saco vitelínico (50\% lipídios) para fornecimento pela ração exógena rica em carboidratos. Nesse período, ocorre aumento brusco no desenvolvimento e número dos enterócitos, promovendo pronunciada polaridade definida na borda em escova da mucosa intestinal; além disso, a presença de alimento no trato digestivo favorece o desenvolvimento dessa superfíce absortiva intestinal (Baranyiová \& Holman, 1976; Moran Jr., 1985).

Uni et al. (1998), estudando frangos Arbor Acres alimentados com ração 36 horas após a eclosão, observaram agrupamentos de microvilos no primeiro dia de idade e criptas com estruturas anormais entre o 70 e o 9 o dia de idade. Sklan \& Noy (2000) observaram que o desenvolvimento da mucosa intestinal de frangos Ross foi prejudicado pelo atraso de 48 horas na ingestão de alimento. Gonzales et al. (2000), em mensurações no intestino delgado de pintos de corte mantidos em jejum alimentar de 18 e 36 horas após alojamento, observaram alterações no comprimento e na altura de criptas, nos pesos absoluto e relativo e no comprimento do intestino.

Gonzáles \& Saldanha (2001) afirmaram que o atraso no fornecimento de alimento pode determinar prejuízos produtivos tardios em aves de rápido crescimento, de modo que o aporte nutritivo do saco vitelínico parece não ser suficiente para suportar o máximo crescimento logo após a eclosão.

A digestão e absorção dos lipídios dependem da presença de sais biliares, da lipase pancreática, da colipase e da proteína ligadora de ácidos graxos, que são dependentes do substrato. Outro fator importante é a imaturidade da circulação enterohepática dos pintos após eclosão (Maiorka, 2002).

Alguns trabalhos têm sido realizados para avaliar a utilização de rações pré-iniciais. Araújo et al. (1999) avaliaram a utilização de ração pré-inicial por 7, 10 ou 14 dias em frangos de corte e verificaram que, em comparação à ração pré-inicial, a ração inicial foi pior em qualquer período de fornecimento. Stringhini et al. (2003) verificaram que a ração pré-inicial nestes mesmos períodos de utilização não influenciou o desempenho de frangos de corte, porém, quando o peso inicial alterou, o ganho de peso, o consumo de ração e o índice de eficiência produtiva pioraram em pintos com peso abaixo de $40 \mathrm{~g}$ no primeiro dia. Reforçando essas informações, Saki (2005) observou que o fornecimento de dietas exógenas deve iniciar no máximo 24 horas após o nascimento.

Freitas et al. (1999) avaliaram a digestibilidade aparente de extrato etéreo (EE) e proteína bruta (PB) para frangos de corte alimentados com rações acrescidas ou não de óleo de soja e encontraram resultados contraditórios. Esses autores observaram alta digestibilidade do EE na primeira semana, acompanhada de redução na segunda semana e de um novo aumento na terceira semana. A digestibilidade da PB foi em torno de $70 \%$ na primeira semana, diminuiu a menos de $60 \%$ na segunda semana e voltou a aumentar aos 21 dias de idade.

Maiorka (2002) avaliou diferentes níveis de energia ou de óleo de soja na dieta pré-inicial de frangos de corte e concluiu que altos níveis de energia, provenientes de lipídios, não melhoram o desempenho (ganho de peso, consumo de ração e conversão alimentar) das aves.

Rocha et al. (2003) testaram a interação entre os níveis de PB (20, 23 e 26\%) e de energia metabolizável (EM) (2.850 e $3.000 \mathrm{kcal} / \mathrm{kg}$ ) e verificaram diferenças no consumo de ração e na conversão alimentar no período de 1 a 7 dias de idade e, ainda, no consumo de ração no período de 1 a 21 dias apenas para os níveis mais altos de proteína.

De acordo com Freitas et al. (2006), o consumo de ração e de nutrientes está relacionado ao conteúdo e à forma de determinação da EM dos alimentos (aparente ou verdadeira determinada com galos ou pintos). Esses autores concluíram que, para formulação da ração de 1 a 21 dias de vida, os valores de EM aparente determinada com pintos promoveram melhor desempenho.

Esta pesquisa foi realizada para avaliar o desempenho de frangos de corte no período de 1 a 21 dias de idade alimentados com rações pré-iniciais ( 1 a 7 dias) com diferentes níveis de EM, determinar os efeitos das rações sobre a digestibilidade e retenção dos nutrientes e mensurar as relações corporais (peso dos órgãos em relação ao peso corporal) e o comprimento dos intestinos das aves no $1^{1}$,, $4 \underline{\underline{0}}$, $7^{\circ}, 10^{\circ}$ e e $14^{\circ}$ dias de idade.

\section{Material e Métodos}

O experimento foi conduzido no Aviário experimental da Escola de Veterinária da Universidade Federal de Goiás, em Goiânia. Foram utilizados 280 pintos de corte machos da 
linhagem Avian $\times$ Cobb, vacinados contra Marek no incubatório e criados em baterias aquecidas até os 21 dias. Foram utilizadas oito baterias de aço galvanizado, equipadas com comedouros e bebedouros do tipo linear e bandejas metálicas para a retirada das excretas. Cada bateria continha cinco andares com divisões de $0,33 \times 0,50 \mathrm{~m}$ somando 20 unidades experimentais. Até os 14 dias de idade, uma lâmpada incandescente de $60 \mathrm{~W}$ foi utilizada para cada andar para aquecimento das aves e complementação das lâmpadas de $200 \mathrm{~W}$ no ambiente. O manejo até os 21 dias de idade incluiu a limpeza diária dos bebedouros, a troca de água e o abastecimento dos comedouros duas vezes ao dia.

O delineamento experimental utilizado foi o inteiramente casualizado com cinco tratamentos (níveis de EM: 2.850, 2.950, $3.000,3.050$ e $3.150 \mathrm{kcal} / \mathrm{kg}$ ), cada um com quatro repetições de 14 aves. As rações foram formuladas à base de milho e farelo de soja para conter diferentes níveis de EM (Tabela 1) e fornecidas às aves durante a primeira semana de vida. Após este período, todas as aves receberam uma ração única para fase inicial (Tabela 1), com 20,8\% de PB e $3.000 \mathrm{kcal} \mathrm{EM} / \mathrm{kg}$, até os 21 dias de acordo com a composição de alimentos, conforme exigências nutricionais preconizadas por Rostagno et al. (2000).
Os pesos das aves, das rações fornecidas e das sobras foram medidos no $1^{\circ}, 4^{\circ}, 7^{\circ}, 10^{\circ}, 14^{\circ}, 18^{\circ}$ e $21^{\circ}$ dias de idade. Foram ainda anotados a mortalidade diária e o peso das aves mortas e calculados o ganho de peso, o consumo de ração e a conversão alimentar.

Realizou-se um ensaio de digestibilidade durante a primeira semana utilizando-se o método da coleta total de excretas (Albino et al., 1992), de modo que os três primeiros dias foram de adaptação às rações experimentais e o período entre o 40 e $7 \underline{0}$ dias foi utilizado para as coletas. As excretas foram recolhidas duas vezes ao dia, acondicionadas em sacos plásticos identificados com o tratamento e a repetição e congeladas para conservação e posteriores análises. Alíquotas foram tomadas, identificadas e pré-secas em estufa retilínea de ventilação forçada (FANEM LTDA) a $55 \pm 5^{\circ} \mathrm{C}$ e posteriormente foram moídas em moinho tipo Wiley para realização das análises, de acordo com a metodologia proposta por Silva (1990), no Laboratório de Nutrição Animal do Departamento de Produção Animal da EV/UFG.

Paralelamente, foram tomadas amostras das rações experimentais e determinados os teores de MS das excretas, a $55^{\circ} \mathrm{C}$, e das rações experimentais, a $105^{\circ} \mathrm{C}$, o nitrogênio

Tabela 1 - Composição das rações fornecidas nas fases pré-inicial e inicial

\begin{tabular}{|c|c|c|c|c|c|c|}
\hline & \multicolumn{5}{|c|}{ Ração pré-inicial (1 a 7 dias) } & \multirow[b]{2}{*}{ Ração inicial } \\
\hline & 2.850 & 2.950 & 3.000 & 3.050 & 3.150 & \\
\hline \multicolumn{7}{|l|}{ Ingrediente } \\
\hline Milho & 58,687 & 55,693 & 53,508 & 51,264 & 49,906 & 59,404 \\
\hline Farelo de soja & 37,018 & 34,903 & 31,070 & 31,891 & 31,768 & 31,247 \\
\hline Sal & 0,448 & 0,453 & 0,461 & 0,457 & 0,461 & 0,439 \\
\hline Glutenose & 0,100 & 2,000 & 5,000 & 5,000 & 5,000 & 2,000 \\
\hline DL-metionina & 0,224 & 0,211 & 0,189 & 0,204 & 0,193 & 0,200 \\
\hline L-lisina & 0,139 & 0,201 & 0,309 & 0,240 & 0,294 & 0,237 \\
\hline Óleo vegetal & 0,100 & 1,344 & 1,228 & 2,727 & 4,142 & 1,422 \\
\hline Amido & 0,100 & 2,000 & 5,000 & 5,000 & 5,000 & 2,000 \\
\hline PB, \% & 22,20 & 22,20 & 22,20 & 22,20 & 22,20 & 20,88 \\
\hline Lisina, \% & 1,307 & 1,307 & 1,307 & 1,307 & 1,307 & 1,239 \\
\hline Metionina + Cistina & 0,926 & 0,926 & 0,926 & 0,926 & 0,926 & 0,879 \\
\hline Metionina, \% & 0,584 & 0,583 & 0,581 & 0,583 & 0,583 & 0,555 \\
\hline Fibra bruta, \% & 3,452 & 3,284 & 3,031 & 3,166 & 3,012 & 3,112 \\
\hline Ca, \% & 0,993 & 0,988 & 0,988 & 0,988 & 0,988 & 0,939 \\
\hline P disponível, \% & 0,466 & 0,466 & 0,466 & 0,466 & 0,466 & 0,441 \\
\hline $\mathrm{Na}, \%$ & 0,224 & 0,224 & 0,224 & 0,224 & 0,224 & 0,216 \\
\hline
\end{tabular}


total, a digestibilidade, determinada conforme descrito por Matterson et al. (1965), e as retenções de MS e PB, determinadas pela quantidade de MS e PB ingerida subtraída da quantidade excretada dividida pelo ganho de peso.

Os dados foram tabulados e analisados utilizando-se o programa SAEG - Sistema de Análises Estatísticas e Genéticas (UFV, 1997), utilizando-se a análise de regressão polinomial.

\section{Resultados e Discussão}

A temperatura ambiente média obtida no período experimental variou de $30,2^{\circ} \mathrm{C}$ (mínima) a $33,8^{\circ} \mathrm{C}$ (máxima).

O desempenho no período de 1 a 7 dias (Tabela 2) não foi afetado pelo aumento dos níveis de EM para frangos na fase pré-inicial, à exceção do efeito cúbico observado para conversão alimentar $\left(r^{2}=47,85 \%\right)$, o que dificultou a interpretação. Esses resultados estão de acordo com os obtidos por Rocha et al. (2003), que avaliaram diferentes níveis de proteína (20, 23 e 26\% PB) e EM (2.850 e $3.000 \mathrm{kcal} / \mathrm{kg}$ ) para frangos de corte na ração pré-inicial e não verificaram efeito no desempenho.

Anteriormente, Maiorka et al. (1997) verificaram maior consumo, menor ganho de peso e piores índices de conversão alimentar para pintos alimentados com diferentes níveis de energia na ração inicial. No entanto, os autores não verificaram diferenças entre os níveis testados (2.900, 3.000 e $3.100 \mathrm{kcal} / \mathrm{kg}$ ) no período de 1 a 7 dias nos parâmetros de desempenho. Teixeira et al. (2002) avaliaram diferentes níveis deEMemrações pré-iniciais (2.900, 2.940, 2.980 e 3.020 kcal $/ \mathrm{kg}$ ) e encontraram valores mais altos para peso médio aos 7 dias de idade e melhor conversão alimentar com 2.980 kcal/kg. Esses autores não verificaram efeito no desempenho de frangos de corte no período de 1 a 42 dias de idade.

Tabela 2 - Desempenho de frangos de corte no período de 1 a 7 dias de idade alimentados com rações pré-iniciais com diferentes níveis de energia metabolizável (EM) na ração

\begin{tabular}{lccc}
\hline $\begin{array}{l}\text { Nível de EM na } \\
\text { ração }(\mathrm{kcal} / \mathrm{kg})\end{array}$ & $\begin{array}{c}\text { Ganho de } \\
\text { peso }(\mathrm{g})\end{array}$ & $\begin{array}{c}\text { Consumo de } \\
\text { ração }(\mathrm{g})\end{array}$ & $\begin{array}{c}\text { Conversão } \\
\text { alimentar }\end{array}$ \\
\hline 2.850 & 116,577 & 138,295 & 1,188 \\
2.950 & 116,767 & 137,418 & 1,179 \\
3.000 & 123,375 & 138,336 & 1,121 \\
3.050 & 109,473 & 133,531 & 1,251 \\
3.150 & 120,046 & 133,608 & 1,118 \\
Efeito & ns & ns & $\mathrm{C}^{2}$ \\
$\mathrm{R}^{2}$ & 6,854 & - & 0,4785 \\
$\mathrm{CV}, \%$ & 4,444 & 4,263 \\
\hline 1 Médias submetidos à análise de regressão. & \\
2 C-efeito cúbico $\left(\hat{\mathrm{Y}}=1269,533-1,2735 X+0,0004259 X^{2}-0,0000000474 X^{3}\right)$.
\end{tabular}

No período de 1 a 21 dias de idade, observou-se efeito linear negativo $(\mathrm{P}<0,05)$ dos níveis de $\mathrm{EM}$ das rações préiniciais no ganho de peso (Tabela 3), diferente do verificado por Teixeira et al. (2002) e Rocha et al. (2003). O valor de $2.859 \mathrm{kcal} / \mathrm{kg}$ permitiu maior ganho de peso no período, semelhante ao valor utilizado por Rocha et al. (2003), de $2.850 \mathrm{kcal} \mathrm{EM} / \mathrm{kg}$. Nascimento et al. (2004) avaliaram diferentes relações energia:proteína bruta (2.850; 3.000 e $3.150 \mathrm{kcal}$ EMAn/kg) e relações EM:PB (125; 136,9 e $151,5 \mathrm{kcal} / \% \mathrm{~PB}$ ) na fase pré-inicial de frangos de corte e verificaram que o nível de $3.150 \mathrm{kcal} \mathrm{EM} / \mathrm{kg}$ de ração promoveu os melhores resultados de conversão alimentar.

Aos 7 dias de idade, verificou-se diferença no peso do coração e no comprimento intestinal (Tabelas 4 e 5). Analisando outras variáveis, observou-se efeito quadrático para peso do intestino e efeito linear positivo $(\mathrm{P}<0.01)$ para peso do fígado com vesícula biliar e para peso do pâncreas.

Segundo Sklan (2001), ocorre rápida transição no suprimento da energia fornecida pelos nutrientes endógenos (saco vitelino) após a eclosão para fornecimento exógeno (ração). Neste período, ocorrem mudanças no tamanho, na morfologia e na função do intestino. A velocidade de maturação dos órgãos do trato gastrintestinal pode ser influenciada pela quantidade de agentes que estimulam o desenvolvimento das mucosas, denominados agentes tróficos (Maiorka et al., 2002). Existem várias classes de agentes tróficos, como as glutaminas, as aminas biogênicas, os mananoligossacarídeos e os ácidos graxos. Os ácidos graxos são importantes para justificar os resultados encontrados neste experimento, pois sua presença em níveis elevados pode ter estimulado o aumento secretório de enzimas digestivas, promovido pela hipertrofia das células secretoras e, conseqüentemente, ter provocado aumento do órgão como um todo (pâncreas e fígado).

Tabela 3 - Desempenho de frangos de corte no período de 1 a 21 dias alimentados com rações pré-iniciais contendo diferentes níveis de energia metabolizável (EM) na ração

\begin{tabular}{lccc}
\hline $\begin{array}{l}\text { Nível de EM na } \\
\text { ração (kcal/kg) }\end{array}$ & $\begin{array}{c}\text { Ganho de } \\
\text { peso }(\mathrm{g})\end{array}$ & $\begin{array}{c}\text { Consumo de } \\
\text { ração }(\mathrm{g})\end{array}$ & $\begin{array}{c}\text { Conversão } \\
\text { alimentar }\end{array}$ \\
\hline 2.850 & 708,574 & $1.057,856$ & 1,553 \\
2.950 & 676,240 & $1.046,250$ & 1,549 \\
3.000 & 698,218 & $1.013,060$ & 1,568 \\
3.050 & 649,655 & 999,334 & 1,567 \\
3.150 & 653,228 & $1.036,246$ & 1,531 \\
Efeito ${ }^{2}$ & $\mathrm{~L}^{2}$ & $\mathrm{~ns}$ & $\mathrm{~ns}$ \\
$\mathrm{R}^{2}$ & 0,6721 & - & - \\
CV & 4,444 & 5,797 & 4,693 \\
\hline
\end{tabular}

${ }^{1}$ Médias submetidos à análise de regressão.

${ }^{2} \mathrm{~L}$ - efeito linear ( $\left.\hat{Y}=1255,044-0,1926 X\right)$; ns - não-significativo. 
Tabela 4 - Medidas de órgãos de frangos de corte aos 7 dias de idade alimentados com dietas pré-iniciais contendo diferentes níveis de energia metabolizável (EM)

\begin{tabular}{|c|c|c|c|c|c|c|}
\hline \multirow{2}{*}{$\begin{array}{l}\text { Nível de EM } \\
\text { na ração (kcal/kg) }\end{array}$} & \multirow[t]{2}{*}{ Peso da ave (g) } & \multicolumn{4}{|c|}{ Peso do órgão (g) } & \multirow{2}{*}{$\begin{array}{c}\text { Comprimento do trato } \\
\text { gastrintestinal }(\mathrm{cm})\end{array}$} \\
\hline & & Intestino & Pâncreas & Fígado & Coração & \\
\hline 2.850 & 171,75 & 14,62 & 0,67 & 6,29 & 1,39 & 113,63 \\
\hline 2.950 & 172,00 & 13,95 & 0,84 & 6,27 & 1,58 & 113,00 \\
\hline 3.000 & 179,00 & 11,49 & 0,84 & 7,17 & 1,43 & 113,13 \\
\hline 3.050 & 163,00 & 11,94 & 0,80 & 7,41 & 1,58 & 114,75 \\
\hline 3.150 & 175,50 & 15,06 & 0,96 & 7,38 & 1,51 & 117,88 \\
\hline $\mathrm{CV}, \%$ & 4,36 & 4,73 & 8,47 & 6,12 & 15,91 & 3,55 \\
\hline Efeito $^{1}$ & ns & $\mathrm{Q}^{2}$ & $\mathrm{~L}^{3}$ & $\mathrm{~L}^{4}$ & ns & ns \\
\hline $\mathrm{R}^{2}$ & - & 0,71 & 0,91 & 0,73 & - & - \\
\hline P (\%) & - & 0,01 & 0,01 & 0,05 & - & - \\
\hline
\end{tabular}

1 Médias submetidas à análise de regressão.

${ }^{2} \mathrm{Q}$ - efeito quadrático ( $\hat{\mathrm{Y}}=1073,731-0,706975 \mathrm{X}+0,0001177143 \mathrm{X}^{2}$ ).

${ }^{3} \mathrm{~L}$ - efeito linear (Peso pâncreas: $\left.\hat{\mathrm{Y}}=-1,819+0,000885 \mathrm{X}\right)$;

${ }^{4} \mathrm{~L}$ - efeito linear (Peso do fígado: $\left.\hat{Y}=-6,3185+0,0044075 X\right)$.

Tabela 5 - Medidas de órgãos obtidos com frangos de corte aos 14 dias de idade alimentados com dietas pré-iniciais contendo diferentes níveis de energia metabolizável (EM)

\begin{tabular}{|c|c|c|c|c|c|c|}
\hline \multirow{2}{*}{$\begin{array}{l}\text { Nível de EM } \\
\text { na ração }(\mathrm{kcal} / \mathrm{kg})\end{array}$} & \multirow[t]{2}{*}{ Peso da ave (g) } & \multicolumn{4}{|c|}{ Peso do órgão (g) } & \multirow{2}{*}{$\begin{array}{l}\text { Comprimento do trato } \\
\text { gastrintestinal }(\mathrm{cm})\end{array}$} \\
\hline & & Intestino & Pâncreas & Fígado & Coração & \\
\hline 2.850 & 457,25 & 23,43 & 1,54 & 14,56 & 4,07 & 117,25 \\
\hline 2.950 & 454,50 & 22,35 & 1,64 & 14,24 & 3,73 & 127,88 \\
\hline 3.000 & 445,25 & 22,58 & 1,55 & 13,16 & 3,66 & 126,33 \\
\hline 3.050 & 443,50 & 24,71 & 1,70 & 15,62 & 4,03 & 127,88 \\
\hline 3.150 & 453,75 & 23,60 & 1,74 & 15,90 & 4,09 & 134,25 \\
\hline $\mathrm{CV}, \%$ & 2,85 & 11,07 & 16,66 & 11,28 & 16,35 & 23,94 \\
\hline Efeito $^{1}$ & ns & ns & ns & ns & ns & ns \\
\hline $\mathrm{R}^{2}$ & - & - & - & - & - & - \\
\hline P, \% & - & - & - & - & - & - \\
\hline
\end{tabular}

${ }^{1}$ Médias submetidas à análise de regressão.

De acordo com Sklan \& Noy (2000), nos primeiros dias após eclosão, há intenso desenvolvimento morfológico e funcional dos órgãos e progressivo aumento na área de absorção e secreção de enzimas, sugerindo que o aumento morfométrico dos órgãos digestivos e a atividade enzimática são coordenados pelo eficiente suprimento de nutrientes.

Confirmando a importância da presença e da quantidade de nutrientes no trato gastrintestinal, Gonzales et al. (2000) avaliaram o intestino delgado de pintos de corte neonatos submetidos a jejum alimentar de 18 e 36 horas após alojamento e observaram grandes alterações no comprimento e na altura de criptas, nos pesos absoluto e relativo dos órgãos digestivos e no comprimento do intestino. Contudo, o aumento morfométrico dos órgãos digestivos nem sempre pode ser considerado fator positivo. Moran Jr. (1994) relatou que a saturação do enterócito com alimentos gordurosos à base de ácidos graxos de cadeia longa diminui a motilidade e o trânsito intestinal, por impedir a formação de lipoproteínas. De acordo com
Ito (1994), a constante ingestão de altos níveis de gorduras determina o aparecimento da degeneração hepática gordurosa, fato observado em $12 \%$ das aves alimentadas com a ração contendo $3.150 \mathrm{kcal} \mathrm{EM/kg}$. Essa degeneração se caracteriza pela perda de consistência e pela forma dos lóbulos hepáticos, que tornam esse órgão de coloração pálida. Neste estudo, nas aves abatidas no $14^{\circ}$ dia de idade, não foi possível observar nenhum efeito $(\mathrm{P}>0,05)$ dos níveis de EM da ração sobre essas variáveis estudadas.

Houve efeito quadrático $(\mathrm{P}<0,05)$ das rações sobre o coeficiente de digestibilidade da MS e efeito cúbico $(\mathrm{P}<0,05)$ sobre o coeficiente de digestibilidade da proteína (Tabela 6).

Analisando a digestibilidade de MS, proteína e EE em pintos alimentados com rações pré-iniciais contendo 2.850 e $3.000 \mathrm{kcal}$ EM/kg, Rocha et al. (2003) não detectaram efeito dos níveis energéticos sobre esses parâmetros. Derivando-se a equação, verificou-se que o ponto de máxima para digestibilidade da MS ocorreu com nível estimado de $3.115 \mathrm{kcal} / \mathrm{kg}$, superior ao sugerido por Rocha et al. (2003), 
Tabela 6 - Coeficientes de digestibilidade e índice de retenção (RET) da MS, do N e da PB em frangos de corte aos 4 e aos 7 dias de idade alimentados com rações pré-iniciais contendo diferentes níveis de energia metabolizável (EM)

\begin{tabular}{|c|c|c|c|c|c|}
\hline \multirow[t]{2}{*}{ Nível de EM na ração (kcal/kg) } & \multicolumn{2}{|c|}{ Coeficiente de digestibilidade } & \multicolumn{3}{|c|}{ Índice de retenção } \\
\hline & MS (\%) & PB (\%) & MS (mg/g) & N (mg/g) & $\mathrm{PB}(\mathrm{mg} / \mathrm{g})$ \\
\hline 2.850 & 73,812 & 63,267 & 934,269 & 26,210 & 163,818 \\
\hline 2.950 & 74,704 & 62,236 & 939,624 & 25,106 & 156,916 \\
\hline 3.000 & 77,635 & 63,421 & 914,346 & 23,145 & 144,655 \\
\hline 3.050 & 77,612 & 57,726 & 1103,124 & 26,158 & 163,490 \\
\hline 3.150 & 77,248 & 64,952 & 976,743 & 26,316 & 164,476 \\
\hline Efeito $^{1}$ & $\mathrm{Q}^{2}$ & $\mathrm{C}^{3}$ & ns & ns & ns \\
\hline $\mathrm{R}^{2}$ & 0,8020 & 0,6835 & - & - & - \\
\hline CV & 0,864 & 2,142 & 9,351 & 9,853 & 9,853 \\
\hline
\end{tabular}

${ }^{1}$ Médias submetidos à análise de regressão.

${ }^{2} \mathrm{Q}$ - efeito quadrático ( $\left.\hat{\mathrm{Y}}=-485,0755+0,3615 \mathrm{X}-0,00005802 \mathrm{X}^{2}\right)$;

${ }^{3} \mathrm{C}$ - efeito cúbico ( $\left.\hat{Y}=-67066,77+67,623 X-0,02268 X^{2}+0,000002535 X^{3}\right)$.

de $2.850 \mathrm{kcal} / \mathrm{kg}$, e à recomendação de Rostagno et al. (2005), de 2.925 a $2.960 \mathrm{kcal} / \mathrm{kg}$, no entanto, esse nível foi próximo ao valor de $3.000 \mathrm{kcal} / \mathrm{kg}$ sugerido por Nascimento et al. (2004). Para o índice de retenção de MS e de PB, não houve efeito dos tratamentos $(\mathrm{P}>0,05)$.

\section{Conclusões}

O aumento do nível de energia metabolizável em rações pré-iniciais à base de milho e farelo de soja piorou o ganho de peso das aves no período de 1 a 21 dias de idade e aumentou a digestibilidade da matéria seca no período préinicial. Os níveis energéticos avaliados também não influenciaram o peso e o tamanho dos órgãos avaliados (intestinos, pâncreas, fígado e coração). O nível de energia metabolizável de $2.850 \mathrm{kcal} / \mathrm{kg}$ permitiu melhor desempenho de frangos de corte e o nível de $3.115 \mathrm{kcal} / \mathrm{kg}$, melhor aproveitamento de matéria seca.

\section{Literatura Citada}

ALBINO, L.F.T.; ROSTAGNO, H.S.; TAFURI, M.L. Utilização de diferentes sistemas de avaliação energética de alimentos na formulação de rações para frangos de corte. Revista da Sociedade Brasileira de Zootecnia, v.21, n.6, p.1037-1046, 1992.

ARAÚJO, C.S.S.; STRINGHINI, J.H.; ARAÚJO, L.F. et al. Manejo nutricional de frangos de corte na fase pré-inicial Archivos Latinoamericanos de Producción Animal, v.7, n.2, p.7784, 1999.

BARANYIOVÁ, E.; HOLMAN, J. Morphological changes in the intestinal wall in fed and fasted chickens in the first week after hatching. Acta Veterinaria Brno, v.45, p.151-158, 1976.

CROOM, W.J.; BRAKE, J.; COLES, B.A. et al. Is intestinal absorption capacity rate-limiting for performance in poultry? Journal of Applied Poultry Research, v.8, p.242-252, 1999.

DIBNER, J. Nutritional Requirements of young poultry. In: MEETING OF ARKANSAS NUTRITION CONFERENCE, 1996, Fayetteville. Proceedings... Fayetteville: Arkansas Poultry Federation, 1996. p.15-27.

FREITAS, B.C.F.; BAIÃO, N.C.; NUNES, I.J. et al. Digestibilidad de la grasa en las primeras semanas de vida del pollo de carne.
In: CONGRESSO LATINO AMERICANO DE AVICULTURA, 16., 1999, Lima. Anais... Lima: Asociación Latinoamericana de Avicultura, 1999. p.356-359.

FREITAS, E.R.; SAKOMURA, N.K.; EZEQUIEL, J.M.B. et al. Energia metabolizável de alimentos na formulação de ração para frangos de corte. Pesquisa Agropecuária Brasileira, v.41, n.1, p.107-115, 2006.

FURLAN, R.L.; MACARI, M. Motilidade gastrintestinal. In: MACARI, M.; FURLAN, R.L.; GONZÁLES, E. (Eds.) Fisiologia aviária aplicada aos frangos de corte. Jaboticabal: FUNEP/UNESP, 2002. p.97-104.

GONZALES, E.; SALDANHA, E.S.P.B. Os primeiros dias de vida do frango e a produtividade futura. In CONGRESSO BRASILEIRO DE ZOOTECNIA, 11., CONGRESSO INTERNACIONAL DE ZOOTECNIA, 3., 2001, Goiânia, Anais... Goiânia: Universidade Católica de Goiás, 2001. p.310-327.

GONZALES, E.; LEANDRO, N.S.M.; VAROLI JR., J.C. et al. O tempo de jejum do neonato e a restrição alimentar quantitativa influenciando a produtividade de frango de corte na idade de abate. Revista Brasileira de Ciência Avícola, supl. 2. p.4, 2000.

ITO, N.M.K. Fisiopatologia do aparelho digestivo. In: FACTA (Ed.) Fisiologia da digestão e absorção das aves. Campinas: Fundação Apinco de Ciência e Tecnologia Avícolas, 1994. 159$170 \mathrm{p}$.

LIMA, I.L. Níveis nutricionais utilizados nas rações pela indústria avícola. In: SIMPÓSIO INTERNACIONAL SOBRES EXIGÊNCIAS NUTRICIONAIS DE AVES E SUÍNOS, 1996, Viçosa, MG. Anais... Viçosa, MG: Universidade Federal de Viçosa, 1996. p.389-401.

MAHAGNA, M.; NIR, I. Comparative development of digestive organs, intestinal disaccharidases and some blood metabolites in broiler and layer-type chicks after hatching. British Poultry Science, v.37, p. 359-371, 1996.

MAIORKA, A.; BOLELI, I.C.; MACARI, M. Desenvolvimento e reparo da mucosa intestinal. In: MACARI, M.; FURLAN, R.L.; GONZÁLES, E. (Eds.) Fisiologia da digestão e absorção das aves. Campinas: Fundação Apinco de Ciência e Tecnologia Avícolas, 2002. p.113-124.

MAIORKA, A. Efeitos da idade da matriz e do agente trófico (glutamina) sobre o desenvolvimento da mucosa intestinal e atividade enzimática do pâncreas de pintos de corte na primeira semana. Jaboticabal: Universidade Estadual Paulista, 2002. 100p. Tese (Doutorado em Zootecnia) - Universidade Estadual Paulista, 2002.

MAIORKA, A.; LECZNIESKI, J.; BARTELS, H.A. et al. Efeito do nível energético da ração sobre o desempenho de frangos de corte de 1 a 7,7 a 14 e 14 a 21 dias de idade. In: CONFERÊNCIA APINCO DE CIÊNCIA E TECNOLOGIA AVÍCOLAS - PRÊMIO 
LAMAS DE PESQUISA AVÍCOLA, 1997, Campinas. Trabalhos de Pesquisa... Campinas: Fundação Apinco de Ciência e Tecnologia Avícolas, 1997. p.18.

MATTERSON, L.D.; POTTER, L.M.; STUTZ, M.W. et al. The metabolizable energy of feeds ingredients for chickens. Storrs: The Univesity of Connecticut, Agricultural Experiment Station, 1965. 11p. (Research Report).

MORAN JR., E.T. Digestion and absorption of carbohydrates in fowl and events through perinatal development. Journal of Nutrition, v.115, n.2, p.665-71, 1985.

MORAN JR., E. Digestão e absorção de gorduras. In: FACTA (Ed.) Fisiologia da digestão e absorção das aves. Campinas: Fundação Apinco de Ciência e Tecnologia Avícolas, 1994. p.71-78.

NASCIMENTO, A.H.; SILVA, J.H.V.; ALBINO, L.F.T. et al. Metabolizable energy and energy: protein ratio for male broiler chicks to pre-starter and starter phases. Revista Brasileira de Zootecnia, v.33, n.4, p.911-918, 2004.

NITSAN, Z.; BEN-AVRAHAM, G.; ZOREF, Z. et al. Growth and development of the digestive organs and some enzymes in broiler chicks after hatching. British Poultry Science, v.32, p.515-523, 1991.

PENZ JR., A.M.; VIEIRA, S.L. Nutrição na primeira semana. In: CONFERÊNCIA APINCO DE CIÊNCIA E TECNOLOGIA AVÍCOLAS, 1998, Campinas. Anais... Campinas: Fundação Apinco de Ciência e Tecnologia Avícolas, 1998. p.121-39.

STRINGHINI, J.H.; RESENDE, A.; CAFÉ, M.B. et al. Efeito do peso inicial dos pintos e do período da dieta pré-inicial sobre o desempenho de frangos de corte. Revista Brasileira de Zootecnia, v.32, n.2, p.353-360, 2003.

ROCHA, P.T.; STRINGHINI, J.H.; ANDRADE, M.A. et al. Desempenho de frangos de corte alimentados com rações préiniciais contendo diferentes níveis de proteína bruta e energia metabolizável. Revista Brasileira de Zootecnia, v.32, n.1, p.162-170, 2003.

ROSTAGNO, H.S.; ALBINO, L.F.T.; DONZELE, J.L. et al. Tabelas brasileiras para aves e suínos: composição de alimentos e exigências nutricionais. Viçosa, MG: Universidade Federal de Viçosa, 2000. 141p.

ROSTAGNO, H.S.; ALBINO, L.F.T., DONZELE, J.L. et al. Tabelas brasileiras para aves e suínos: composição de alimentos e Exigências nutricionais. 2.ed. Viçosa, MG: Universidade Federal de Viçosa, 2005. 186p.

RUTZ, F. Secreções digestivas. In: FACTA (Ed.) Fisiologia da digestão e absorção das aves. Campinas: Fundação Apinco de Ciência e Tecnologia Avícolas, 1994. p.19-24.

SAKI, A.A. Effect of post-hatch feeding on broiler performance. International Journal of Poultry Science, v.4 n.1, p.4-6, 2005. Disponível em: http://www.pjbs.org/ijps/fin243.pdf, Accesso em: 10/9/2006.

SILVA, D.J. Análise de alimentos (métodos químicos e biológicos), 2.ed. Viçosa, MG: Universidade Federal de Viçosa, 1990. 165p.

SKLAN, D. Development of the digestive tract of poultry. World's Poultry Science Journal, v.57, n.4, p.415-428, 2001.

SKLAN, D.; NOY, Y. Hidrosysis and absortion in the small intestines of posthatch chicks. Poultry Science, v.79, p.1306-1310, 2000.

TEIXEIRA, A.W.F.; FERNANDES, E.A.; BARROS, V.M. et al. Efeito de diferentes níveis de energia na ração pré-inicial sobre o desempenho de frangos de corte. Revista Brasileira de Ciência Avícola, supl. 4, p.61, 2002.

UNIVERSIDADE FEDERAL DE VIÇOSA - UFV. SAEG - Sistema de análises estatísticas e genéticas. Versão 7.1. Viçosa, MG: 1997. 150p. [Manual do usuário].

UNI, Z.; GANOT, S.; SKLAN, D. Posthatch development of mucosal function in the broiler small intestine. Poultry Science, v.77, p.75-82, 1998. 